\title{
COMENTARIO
}

\section{El enfoque interdisciplinario en los estudios del discurso}

\author{
María Susana González Reyna
}

$\mathrm{L}$ a sociedad de la información ha dado lugar a que el derrotero en los estudios del discurso se amplíe considerablemente, a la vez que ha reforzado su carácter inter, multi y transdisciplinario. En este escenario, se ha favorecido también la relación entre la lingüística y la semiótica con el proceso de la comunicación, de naturaleza esencialmente social. Diversas modalidades de análisis del discurso se han insertado con gran fuerza en los procesos comunicativos que tienen como propósito la reflexión teórica y la aplicación metodológica correspondiente para entender mejor las prácticas comunicativas que van desde las estrictamente personales hasta las realizadas ante grandes públicos. El discurso y su metodología se sitúan en una amplia perspectiva que incluye varias disciplinas, como la pragmática, la sociolingüística, la psicología, la antropología, la gramática del texto, la etnografía y la política, entre muchas más. En igual sentido, resaltamos la amplia gama de discursos que son objeto de análisis. A modo de ejemplo señalamos en lo general el discurso político, el religioso, el periodístico - prensa, radio, televisión, internet-, el cine, los nuevos discursos producto de las nuevas tecnologías - mensajes de texto, blogs, tweets-. En lo particular, baste con atender la variedad temática y de perspectivas teóricas y metodológicas en el análisis discursivo de los textos que componen la sección "Saberes y razones" de este número de Desacatos. En este conjunto destaca la política como tema principal, pero en la especificidad la referencia varía por la relación que se hace con otros grandes tópicos, como la salud, la identidad nacional, los procesos sociales, la construcción del protagonista relevante, las tramas argumentales parlamentarias, la difusión ideológica y, finalmente, la desigualdad y la exclusión. Llama la atención el énfasis puesto en conocer la realidad de México. Sólo uno de los textos se refiere a un acontecimiento que, si bien es extranjero, por su relevancia política impactó fuertemente en la ideología de la sociedad mexicana.

El texto de Alicia Llamas Martínez Garza, "El significado del silencio entre moradores de La Castañeda en los albores del siglo xx. Consideraciones metodológicas para su tratamiento", marca una diferencia sustantiva respecto del texto siguiente por la perspectiva teórica del discurso y por la metodología de análisis aplicada. De inicio, indica que el análisis del discurso es una práctica de investigación y que éste no sólo es la materialidad expresada en el

María Susana González Reyna: Facultad de Ciencias Políticas y Sociales, Universidad Nacional Autónoma de México,

Distrito Federal, México

sgreyna@prodigy.net.mx

Desacatos, núm. 43, septiembre-diciembre 2013, pp. 101-108 
texto, sino también es el discurso oral y, muy especialmente, el discurso del silencio. En lo que se refiere al marco teórico desde el cual se realiza la caracterización del discurso y por ende su análisis son varias las escuelas de pensamiento y autores que guían su investigación. Entre otros, me refiero a los que me parecen fundamentales: Foucault (1979), para la caracterización de la otredad en los enfermos y delincuentes; van Dijk (2003), para explicar la interacción comunicativa en grupos sociales con características específicas, y en la cual la dimensión social del lenguaje juega un papel central al modular la expresión de las emociones, mismas que la autora explica como herramientas de representación de las complejas formas de interacción social dentro de un grupo; Pêcheux (1978), para dar testimonio del manejo de la ideología en el discurso, y la importancia de la posición de los sujetos en los procesos sociales en los cuales éste se expresa, ya sea en palabras y/o en silencios, y Hodge y Kress (1993) para analizar el discurso del poder y del control a través historias poscoloniales en el Continente Americano. Aunque en estricto sentido Bak-Geller no recurre a la propuesta teórica y metodológica del análisis del discurso, hace referencia a los elementos narrativos que remiten a imágenes fundadoras de la idea de nación en los recetarios americanos. Ello se debe, añade la autora, a "la valorización de los productos nativos del país", a "la legitimación del español vernáculo, así como a la implementación de un lenguaje culinario nacional" y a "la emergencia de una nueva noción de tiempo histórico a través de la apropiación y reinvención de las cocinas precoloniales".

Asimismo, y desde la perspectiva arriba indicada, resulta de gran valor para los estudiosos del discurso que, como anota Bak-Geller, en la narrativa culinaria mexicana los autores de los recetarios, además de realzar los ingredientes locales y los platillos típicos del país, empleen términos que en el discurso americanista adquieren un nuevo significado y un nuevo alcance cuando aparecen impresos en las páginas de los primeros libros de cocina mexicana. En adición al valor que en los estudios del discurso cumple la resignificación por la vinculación de los términos con el contexto social y cultural, cabe enfatizar la importancia del tema central del texto en el sentido de que el discurso culinario en México desplegó un lenguaje propio para reforzar la identidad nacional. Como último elemento narrativo del discurso culinario que nos parece importante comentar por su relevancia para el análisis del discurso está el interés de los primeros recetarios mexicanos por construir los antecedentes históricos de la nación. Mediante la "aztequización" de las recetas locales, es decir, el uso del antiguo náhuatl en los ingredientes y títulos de las recetas, los promotores de los recetarios mexicanos aluden a una época gloriosa que se erige como antecedente ilustre de la cocina nacional. El texto proporciona una novedosa y original mirada interdisciplinaria con fuertes tintes históricos y antropológicos para documentar el valiosísimo papel del discurso culinario en la construcción de significados y, derivado de ello, de una identidad mexicana. 
El texto escrito por Eva Salgado Andrade y Frida Villavicencio Zarza, "Reconstrucción periodística de nuevas formas de vida democrática ('la Marcha del Silencio', abril de 2005)", muestra la aplicación de una metodología para el análisis del discurso desde dos perspectivas teóricas: por un lado, la semántica, con John Lyons, para quien el estudio del significado en el uso del lenguaje debe necesariamente vincularse al contexto en el cual se manifiesta; y por otro, con Teun van Dijk (1980, 1990), Norman Fairclough (1995) y Norman Fairclough y Ruth Wodak (2000), cuyas aportaciones al estudio del análisis del discurso sirven a las autoras para vincular el objeto del análisis con la otra perspectiva teórica: el discurso periodístico. Las autoras bien atienden el principio del análisis del discurso que exige no sólo la relevancia temática sino el momento coyuntural del acontecimiento. En este sentido, escogen para su análisis discursivo la llamada "Marcha del Silencio" del 24 de abril de 2005 en la ciudad de México, que puede calificarse como el discurso social de un millón de personas para expresar de forma pacífica y silenciosa el repudio al desafuero del entonces jefe de Gobierno del Distrito Federal Andrés Manuel López Obrador. El análisis que se lleva a cabo pone el acento en todo el marco contextual, que desde una perspectiva semiótica resalta que el silencio de las voces, referido a la oralidad, se acompaña de otras manifestaciones lingüísticas escritas, como las pancartas y las mantas, y otras expresiones discursivas, como las propias del vestido, en este caso los disfraces.

El análisis discursivo, a diferencia de otras formas de hacerlo, inicia desde el momento mismo en que las autoras precisan que el acontecimiento de la marcha, por su contundencia, debió haber sido el tema principal de los titulares de la prensa y no

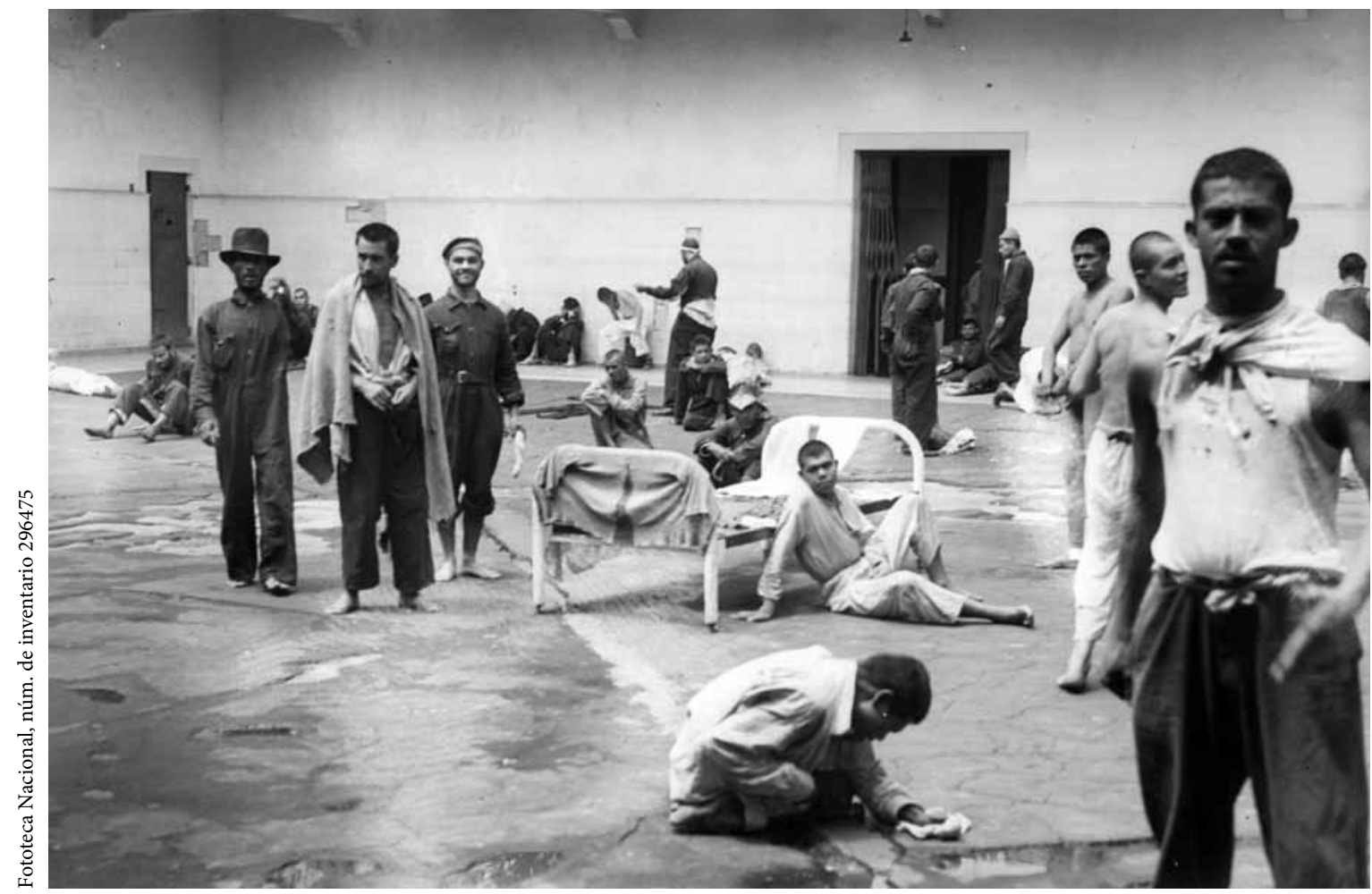

Enfermos mentales en los patios del Manicomio de La Castañeda. 
quedar relegado a segundo plano, toda vez que lo que se destacó fue el destape de López Obrador como candidato para las elecciones presidenciales de 2006. La perspectiva teórica de este texto relaciona de manera estrecha la semiótica discursiva de la prensa con el uso de la política y el poder. El manejo de los hechos y el análisis que se aplica al discurso de la prensa confirma lo dicho por Héctor Borrat (1989) en el sentido de que el periódico es un actor político. Y cabe añadir que lo es no sólo por el poder de la palabra y su difusión masiva, sino por el manejo discursivo de acentuar o silenciar acontecimientos en la conformación del discurso periodístico. Y, en especial, en el texto que comentamos, por el hecho de que deviene altamente revelador, al paso de los años, el significado político que adquiere el discurso con el tratamiento que le dio la prensa. El corpus para el análisis discursivo cubre 15 diarios nacionales. Se le prestó especial atención a los titulares, de conformidad a lo establecido por Kress y van Leeuwen (1998), para quienes - como asientan las

autoras- éstos representan una selección y jerarquización determinadas por quien los produce, en tanto que la selección del tema, la redacción y presentación gráfica del titular que ocupa la nota de primera plana es un indicador relevante para entender la posición — política, económica y social— desde la cual un periódico expone el hecho noticioso y desde la cual interacciona con otros interlocutores sociales.

En la aplicación metodológica del análisis discursivo es relevante el papel que desempeña el análisis lingüístico. Salgado y Villavicencio conjuntan el análisis lingüístico con las exigencias de la redacción periodística para analizar los titulares, materia prima de su corpus. Con base en las características del discurso periodístico, se tomó en cuenta que en la redacción de los titulares hay elisiones, anáforas, metáforas y discurso citado, así como la tipografía y el espacio ocupado, entre otros recursos propios de la redacción periodística y de la síntesis comunicativa que ésta exige. Para un mejor análisis discursivo de la "Marcha del Silencio" de la cual hablaron los periódicos, es, a nuestro parecer, afortunada la combinación que las autoras hacen de la lingüística y la redacción periodística, y el que clasificaran los titulares como expresivos, apelativos, informativos o como actos de habla, de acuerdo con las características gramaticales definidas por Armentia y Caminos (2003). Otra combinación basada en esta misma perspectiva interdisciplinaria es la que realizan al conjuntar los principios de la gramática - morfología y sintaxis - con la dimensión pragmática de los titulares para encontrar el sentido de los titulares y determinar así el tópico principal, el cual, junto a los subtópicos, construye - como ellas explican- "la escena discursiva de la que da cuenta la noticia”. Salgado y Villavicencio indican que en el discurso del periódico se advierten dos protagonistas: la marcha y Andrés Manuel López Obrador; y determinan tres temas: el número de participantes, el objetivo de la marcha y el reconocimiento individual de algunos de los participantes en ella. En suma, con el análisis del discurso que desarrollan las autoras se aprecia la riqueza que aporta la interdisciplinariedad a esta materia. En este caso, con base en la lingüística se recurre a las categorías gramaticales y a la construcción de los enunciados, con el propósito de explicitar la carga ideológica que conlleva nombrar, determinar a los sujetos y sus acciones $y$, especialmente, señalar el papel político que desempeña la prensa en el ejercicio del poder y su implícita y explícita participación política bajo el disfraz del libre ejercicio del derecho a informar.

Irma Mariana Gutiérrez Morales, en “Tramas argumentales en el debate legislativo sobre el aborto", habla de otra de las grandes opciones interdisciplinarias del análisis del discurso: el análisis de las estrategias argumentativas utilizadas por los legisladores del Distrito Federal en los debates que tuvieron lugar de noviembre de 2006 a abril de 2007 en relación con las reformas al Código Penal para despenalizar el aborto. Aunque el tema del aborto es añejo y al respecto se ha dicho y escrito mucho desde perspectivas diversas e incluso contrarias, no es un tema agotado. El análisis discursivo de la autora aprovecha la coyuntura de su reaparición como 
tema central en la vida cotidiana de México debido a su práctica clandestina, a las muertes que ello provoca y a que, en suma, es un problema de índole social no atendido como se requiere por las instancias de gobierno. En la perspectiva teórica del análisis que se propone está claro el tratamiento interdisciplinario: la teoría del discurso político (Giménez, 2008), las especificidades del discurso parlamentario (Carbó, 1996) por su formato y por los actores involucrados, el manejo del poder (Foucault, 1988), la ideología que acompaña toda expresión discursiva (Pêcheux, 1978) y todo ello desde la teoría de la argumentación, siguiendo a Grize (1990), Vignaux (1986) y Plantin (2005). Por medio de su análisis, la autora pone al descubierto los objetos discursivos predominantes en la argumentación de los legisladores, las tramas argumentales que se tejieron en torno al tema del aborto y lo que, a nuestro parecer, resulta un importante hallazgo: la manifestación discursiva de las alianzas y las confrontaciones expresadas en el uso del lenguaje y en la estrategia de la argumentación.

Para la explicación de la forma en que actuaron discursivamente los legisladores, Gutiérrez Morales se basa en la teoría de los actos de habla y en el modelo propuesto por Eva Salgado (2003) para identificar lo que se dice al decir y para situar a los legisladores en su posición de aliados o adversarios en el entramado argumental del debate. Lo que al respecto surge con la aplicación del análisis sirve al propósito de enfatizar el carácter ideológico y político del discurso parlamentario, que rebasa por mucho el ámbito jurídico que por naturaleza le corresponde. Resulta muy afortunada la forma en que la autora retoma a Jean-Blaise Grize (1990) para explicitar la tesis, los argumentos y el entrecruzamiento de los discursos legislativos, y en especial las características que le dieron solidez y verosimilitud a lo expuesto por los legisladores durante el debate parlamentario. Asimismo, es útil para aclarar los criterios en el uso del lenguaje que al construir el discurso no hace referencia al todo externo, sino sólo a aquello que le interesa destacar y que la autora, con base en Grize, llama "esquematización". En la misma línea de aplicar la teoría de la argumentación en el análisis discursivo, la inclusión de Georges Vignaux (1986) sirve al propósito de elucidar las operaciones de pensamiento de los sujetos enunciadores, mismas que, como observa la autora, son una valiosa evidencia empírica que enlaza lo cognitivo con lo lingüístico y su funcionamiento sociocognitivo, toda vez que en el análisis que se lleva a cabo es imperiosa la ubicación del hablante - el legislador- y las determinaciones extradiscursivas. Destacan, por último, las gráficas que presenta la autora y que resultan del análisis discursivo de cada participación en el debate parlamentario en relación con los distintos objetos discursivos: aborto, despenalización/penalización, vida, referéndum y promotores/detractores de la reforma. Son una aportación original y de valía analítica indiscutible como sugerencia metodológica para el análisis del discurso.

Desde el mismo título: "Conocer y comprender al otro: la comunicación intercultural de Al-Qaeda”, el artículo de Evelyn Norma Castro Méndez enfatiza el carácter interdisciplinario en todo análisis del discurso y deja ver que se trata de un análisis en el cual la ideología juega un papel determinante, lo mismo que el significado de las palabras y el diferente contexto sociocultural en el cual se origina el discurso y en el cual es recibido. El análisis se centra en el discurso de la organización islámica Al-Qaeda. El marco teórico-metodológico que guía esta investigación está basado en las teorías semióticas de Roland Barthes y de Umberto Eco, en las macroestructuras semánticas de Teun A. van Dijk y en las aportaciones de Ruth Wodak en lo que se refiere al análisis crítico del discurso, perspectiva que resulta adecuada para la investigación del análisis del discurso de esta organización islámica por el énfasis que pone en el discurso ajeno, el discurso del otro - visión antropológica-, que a veces no comprendemos en su cabal significado por las diferencias étnicas, religiosas y culturales, entre otras, de los grupos sociales. La explicación que Castro Méndez formula al inicio de su exposición revela la importancia que 


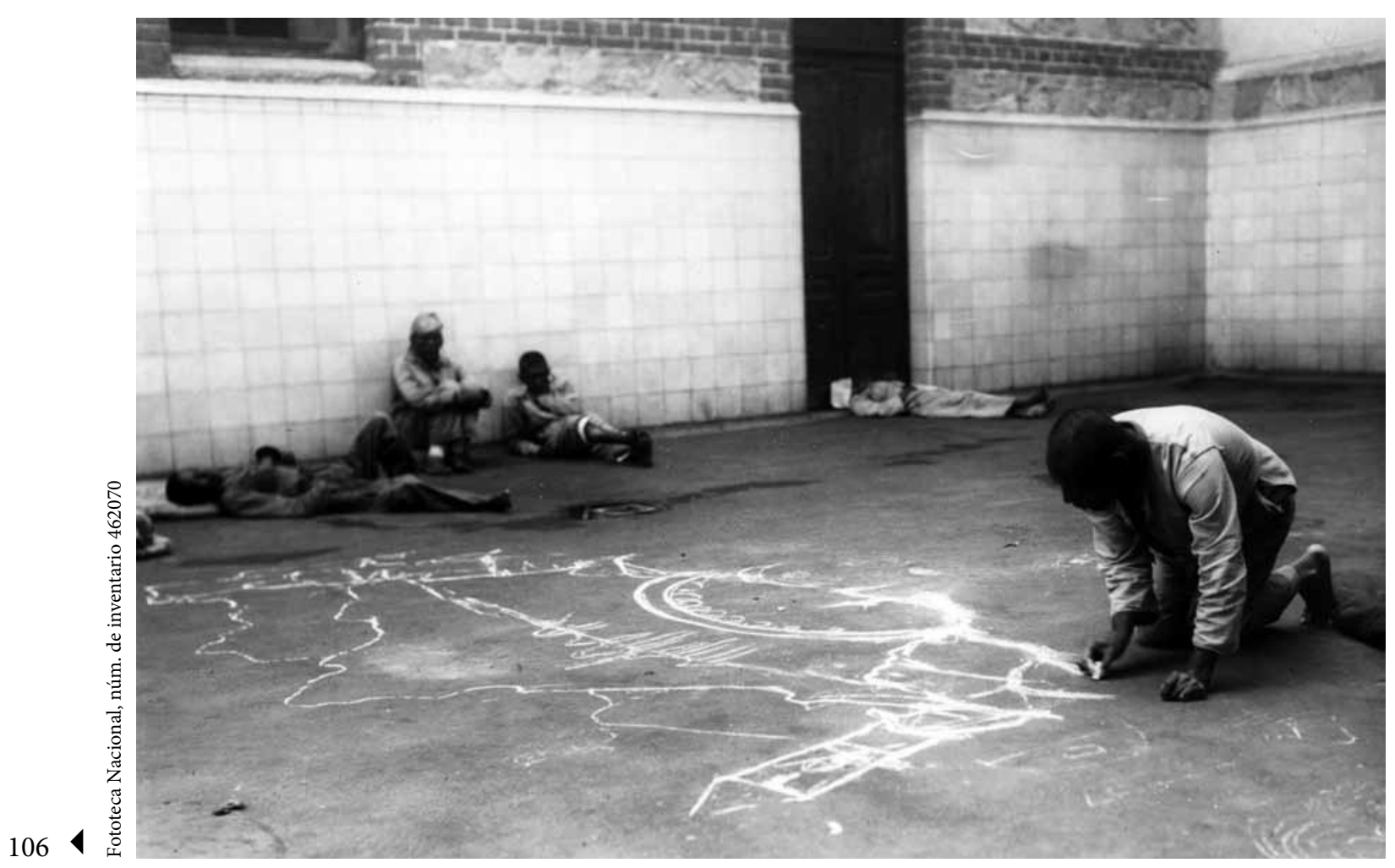

Enfermos descansando y dibujando con gis. Manicomio General de la Ciudad de México.

tiene en el ámbito de la globalización actual el análisis del discurso que lleva a cabo. La tecnología permite que los sujetos de diversas partes del mundo tengan acceso, en todo momento, al discurso del otro. Sin embargo, ello no significa que siempre se le comprenda en su dimensión comunicativa correcta. Es más, con frecuencia el acceso a dichos discursos es fuente de conflicto y confrontación por la decodificación de lo dicho en contextos políticos, sociales y culturales muy diversos en los cuales no coinciden los códigos en la producción discursiva con los de su comprensión, lo cual origina incomprensión. La autora cita a Marc Augé en este punto:

el hombre es un animal simbólico, necesita establecer con otras personas una relación de lenguaje y de pensamiento. Cuando el lenguaje es sustituido o subvertido por imágenes o estereotipos, la relación simbólica deja de ser posible y aparece la violencia (Augé 2002: 37).
El discurso mediático occidental, que juega un papel central en el flujo informativo global, ha decodificado inadecuadamente el discurso del mundo musulmán y ha difundido y fomentado una información que no expresa el significado del discurso original. El análisis de Castro Méndez nos advierte de esta situación, pero además se aventura a una explicación de lo que en realidad ha expresado el discurso de los musulmanes en general y, específicamente, el discurso del tan temido Al-Qaeda. La autora detalla que no es fácil entender el significado del discurso de Al-Qaeda porque, en primer lugar, es un objeto de investigación impreciso en términos científicos; en segundo lugar, en razón de que ya se le identificó en Occidente como un grupo terrorista $y$, en consecuencia, su discurso se empata con la violencia y, en tercer lugar, debido a que los especialistas estudiosos del Medio Oriente no coinciden en 
su percepción y explicación del islamismo. En la metodología del análisis del discurso se exige definir a los interlocutores y el contexto en el cual se lleva a cabo la interlocución.

El corpus para el análisis está conformado por tres comunicados: 2001, 2004 y 2005, que corresponden a los atentados contra Estados Unidos, Madrid y Londres, respectivamente. Para el análisis de los actores la autora se basa en el modelo propuesto por Eva Salgado (2003), quien retoma los actos de habla de Austin y Searle para identificar la función performativa de los actores en dichos comunicados: la autoconstrucción de Al-Qaeda - verdaderos musulmanes-, la construcción de interlocutores - aliados, el resto de los musulmanes y el resto del mundo-, la construcción de adversarios - aliados de Estados Unidos, gobiernos y clérigos musulmanes, infieles y cruzados, hipócritas y apóstatas-, la construcción del referente y el referente sin adornos. Otro de los aspectos a resaltar en este análisis se refiere a la necesidad de identificar las palabras clave de los discursos y precisar su significado en el contexto sociocultural y político en el cual fueron expresadas. Así, Castro Méndez selecciona y define los conceptos de "fieles", "infieles", "cruzados", "apóstatas" e "hipócritas" porque considera que son esenciales para comprender el esquema de pensamiento de la red respecto de la correlación de fuerzas que permea el escenario internacional, y actúa bajo parámetros que no tienen que ver únicamente con asuntos de credo o valores, sino con alianzas políticas y formas de actuación en materia política. La identificación de las acciones discursivas en los comunicados permitió elucidar el esquema de pensamiento que rige la ideología de la red (Castro Méndez, en este volumen)

Además de los relevantes aportes metodológicos para el análisis del discurso arriba señalados, cabe resaltar la explicación sobre el significado del mensaje central del discurso de Al-Qaeda que se desprende de su análisis, una vez establecido el contexto sociocultural y político musulmán. La autora concluye que al movimiento le interesa difundir quiénes son, cuál es su ideología y aclararle al mundo los motivos que los llevan a una actuación política violenta y contrarrestar la corriente de desprestigio que enfrenta. Sus discursos son, en suma, una crítica a la política exterior estadounidense y una enfática denuncia de los agravios históricos que han encarado y ante los cuales la comunidad internacional no ha reaccionado, de tal modo que asumen el terrorismo como una medida última a la que tuvieron que recurrir para defenderse.

\section{BIBLIOGRAFÍA}

Armentia Caminos, José Ignacio y José María Caminos Marcet, 2003, Fundamentos de periodismo impreso, Ariel, Barcelona.

Augé, Marc, 2002, Diario de guerra. El mundo después del 11 de septiembre, Gedisa, Barcelona.

Benveniste, Émile, 2004, Problemas de lingüística general, Siglo XXI, México.

Borrat, Héctor, 1989, El periódico, actor político, Gustavo Gili, México.

Carbó, Teresa, 1996, El discurso parlamentario mexicano entre 1920 y 1950. Un estudio de caso en metodología de análisis de discurso, Centro de Investigaciones y Estudios Superiores en Antropología Social, El Colegio de México, México.

Fairclough, Norman y Ruth Wodak, 2000, "Análisis crítico del discurso", en Teun A. van Dijk (comp.), El discurso como interacción social. Estudio sobre el discurso, Gedisa, Barcelona, pp. 367-404.

Foucault, Michel, 1966, Las palabras y las cosas, Siglo XXI, México.

__, 1979, Enfermedad mental y personalidad, Paidós, Buenos Aires.

_, 1988 , "El sujeto y el poder", en Hubert Dreyfus y Paul Rabinow, Michel Foucault: más allá del estructuralismo y la hermenéutica, Universidad Nacional Autónoma de México, México.

Fowler, Roger, Robert Hodge, Gunther Kress y Tony Trew, 1983, Lenguaje y control, Fondo de Cultura Económica, México.

Giménez, Gilberto, 2008, El debate político en México a finales del siglo xx. Ensayo de análisis del discurso, Universidad Nacional Autónoma de México, México.

Grize, Jean-Blaise, 1990, Logique et langage, Ophrys, París.

Hodge, Robert y Gunther Kress, 1993, El lenguaje como ideología, Routledge, Londres. 
Jakobson, Roman, 1971, Ensayos de lingüística general, Seix Barral, Barcelona.

Kress, Gunther y Theo van Leeuwen, 1998, "Front Pages: (the Critical) Analysis of Newspaper Layout", en Allan Bell y Peter Garrett, Approaches to Media Discourse, Blackwell Publishers, Oxford, pp. 186-219.

Lyons, John, 1981, Lenguaje, significado y contexto, Paidós, Barcelona.

Pêcheux, Michel, 1978, Hacia el análisis automático del discurso, Gredos, Madrid.

Plantin, Christian, 2005, La argumentación, Ariel, Barcelona.

Salgado Andrade, Eva, 2003, El discurso del poder. Informes presidenciales en México (1917-1946), Centro de Investigaciones y Estudios Superiores en Antropología Social, Porrúa, México.
Searle, John, 1993, Actos de habla, Planeta, México. van Dijk, Teun A., 1980, Estructura y funciones del discurso, Siglo XXI, México.

, 1990, La noticia como discurso. Comprensión, estructura y producción de la información, Paidós, Barcelona.

(comp.), 2003, El discurso como interacción social. Estudios sobre el discurso, Gedisa, Barcelona.

van Leeuwen, Theo, 2005, Introducing Social Semiotics, Routledge, Londres.

Verón, Eliseo, 1992, La semiosis social, Gedisa, Madrid.

Vignaux, Georges, 1986, La argumentación. Ensayo de lógica discursiva, Hachette, Buenos Aires.

Wodak, Ruth y Michael Meyer, 2003, Métodos de análisis crítico del discurso, Gedisa, Barcelona. 